\title{
Postoperative Analgesic Efficacy of Different Volumes and Masses of Ropivacaine in Posterior Brachial Plexus Block
}

\author{
Bruno Salome de Morais, TSA ${ }^{1}$, Marcos Guilherme Cunha Cruvinel, TSA ${ }^{2}$, Fabiano Soares Carneiro, TSA ${ }^{3}$, \\ Flavio Lago ${ }^{4}$, Yerkes Pereira Silva ${ }^{5}$
}

\begin{abstract}
Morais BS, Cruvinel MGC, Carneiro FS, Lago F, Silva YP - Postoperative Analgesic Efficacy of Different Volumes and Masses of Ropivacaine in Posterior Brachial Plexus Block.

Background and objectives: The efficacy of posterior brachial plexus block for shoulder surgeries is demonstrated by different authors. However, there is no consensus on the ideal mass and volume of local anesthetic to be employed. The objetive of this study was to compare different volumes and masses of ropivacaine in posterior brachial plexus block in arthroscopic surgeries of the shoulder.

Method: Sixty patients > 18 years, physical status ASA I and II, scheduled for unilateral arthroscopic surgeries of the shoulder were randomly placed in three groups: A (10 mL to $0.5 \%)$, B ( $20 \mathrm{~mL}$ to $0.5 \%$ ), C (5 mL to $1 \%$ ). The block was performed with a $22 \mathrm{G}$ needle of $100 \mathrm{~mm}$ connected to neurostimulator, in a point $3 \mathrm{~cm}$ lateral to the midpoint of $\mathrm{C} 6$ and $\mathrm{C} 7$ interspace, being injected the solution corresponding to each group. The postoperative pain was evaluated at the recovery room and within the first 24 hours of the postoperative period. The groups were compared on length of time until the first complaint of pain, visual numeric scale (VNS) score and morphine consumption within the first 24 hours.
\end{abstract}

Results: There was no statistically significant difference between the three groups related to age, weight and height. There was no difference in length of time until the first complaint of pain, VNS scores over three and morphine consumption in the postoperative period between the groups.

Conclusions: This study concluded that $5 \mathrm{~mL}$ of $1 \%$ ropivacaine promoted analgesic efficacy similar to $10 \mathrm{~mL}$ or $20 \mathrm{~mL}$ of $0.5 \%$ ropivacaine in the posterior brachial plexus block using neurostimulator.

Keywords: Anesthetics, Local, ropivacaine; Pain Measurement; Orthopedics; Brachial Plexus.

\section{INTRODUCTION}

Arthroscopic surgeries of the shoulder became a frequent and common reality as they are less invasive, therefore, offering a faster recovery. Those surgeries are associated with highly intense algic stimulus in the postoperative period, and some types of regional anesthesia are recommended to control the pain in those procedures. Several techniques, volumes and concentrations of different local anesthetics have been used,

Received from Lifecenter Hospital, Brazil.

1. MSc; PhD Student in Healthcare Science at Universidade Federal de Minas Gerais (UFMG); Member of the Anesthesia Committee in Organ Transplantation, Anesthsilogist of Lifecenter Hospital and Hospital das Clínicas, UFMG

2. Specialist in General Medicine, Certificate of Work in Pain, Anesthesiologist at Lifecenter Hospital

3. CET Instructor Hospital da Cíónicas UFMG, Anesthesiologist at Lifecenter Hospital and Hospital da Clínicas of UFMG

4. Specialist in Orthopedics; Orthopedian at Lifecenter Hospital

5. Specialist in Anesthesiology and Pediatrician; MSc and PhD in Healthcare Science by

UFMG; Professor at the Postgraduation Program in Health Science - Child and Adolescent

Health, UFMG, Anesthesiologist at Lifecenter Hospital

Submitted on Fabruary 8, 2011.

Approved on May 19, 2011.

Correpondence to:

Dr. Bruno Salome de Morais

Av. do Contorno, 4747, Serra

30110090 - Belo Horizonte, MG, Brasil

E-mail: brunomoraisanest@yahoo.com.br but there is no clear definition of an ideal combination to be used.

Even though the posterior brachial plexus block or cervical paravertebral block is not a new technique, only recently it had its popularity increased. Its efficacy for both shoulder and proximal humerus surgeries has been evidenced by many authors ${ }^{1-4}$.

Regarding the volume used a recent study showed that the interscalene brachial plexus block guided by ultrasonography with $5 \mathrm{~mL}$ of $0.5 \%$ ropivacaine had the same analgesic efficacy of the group where $20 \mathrm{~mL}$ of $0.5 \%$ ropivacaine was used, but with lower incidence of diaphragmatic paralysis ${ }^{5}$.

So far the analgesic efficacy of posterior brachial plexus block with $5 \mathrm{~mL}$ of ropivacaine without the help of ultrasonography has not been evaluated.

Thus, the objetive of this study was to compare different volumes and masses of ropivacaine in posterior brachial plexus block on the quality of postoperative analgesia of arthroscopic surgeries of the shoulder.

\section{METHOD}

After approval by the institution's Ethics Committee in Research, and signing an informed consent form, 60 patients $>18$ years, physical state ASA I and II, scheduled for uni- 
lateral arthroscopic surgeries of the shoulder (acromioplasty, repair of rotator cuff lesion, treatment of recidivating luxation of shoulder or a combination of those procedures) were randomly placed in three groups, receiving different solutions of ropivacaine: A ( $10 \mathrm{~mL}$ to $0.5 \%$ ), B ( $20 \mathrm{~mL}$ to $0.5 \%), \mathrm{C}(5 \mathrm{~mL}$ to $1 \%)$. The following patients were excluded from the study: the ones with case history or laboratory exams that indicate change of coagulation, previous neurological deficit, serious chronic obstructive pulmonary disease, mental deficit that hinders the comprehension of the scale of pain, body mass index over 45, allergy to local anesthetic, cutaneous infection on the place of the block or contraindication to use dipyrone, nonsteroidal anti-inflammatory drugs (NSAIDs), dexamethasone or clonidine.

Monitoring consisted of ECG, pulse oximetry and automatic, non-invasive blood pressure. Patients were placed on lateral decubitus, with the shoulder to be operated up, the head on a pillow and lowered over the neck. Then, patients were sedated to remain calm, cooperative and answering verbal commands. For doing so, it was used $1 \mu \mathrm{g} \cdot \mathrm{kg}^{-1}$ of fentanyl and $3 \mathrm{mg}$ of intravenous midazolam. The spinous processes $\mathrm{C} 6$ and $\mathrm{C} 7$ were marked on the skin with dermographic pen. The puncture point used was $3 \mathrm{~cm}$ lateral to the space between the above-mentioned spinous processes. After antisepsis of the skin with degerming and alcoholic Povidoneiodine (PVP-I), an anesthetic button with lidocaine $1 \%$ without adrenaline was applied with an insulin needle. A 22G needle, $100 \mathrm{~mm}$ long (Stimuplex A100 BBraun, Melsunger, Germany) connected to the neurostimulator (Stimuplex-DIG, BBraun Melsungen, Germany) with the initial setting of $1 \mathrm{~mA}$, length of stimulation of $0.1 \mu \mathrm{s}$, and frequency of $2 \mathrm{~Hz}$ was introduced perpendicular to the skin until a motor response was obtained. Motor responses of the levator scapulae, deltoid, or biceps muscles were acceptable and the loss of this response from $0.6 \mathrm{a} 0.3 \mathrm{~mA}$. After verifying the negative aspiration of blood, $2 \mathrm{~mL}$ of $2 \%$ lidocaine with 1:200,000 adrenaline was injected. Then, the ropivacaine was injected in incremental doses of $5 \mathrm{~mL}$.

Groups were divided as follows, without the knowledge of the surgeon, patient or anesthetist responsible for the evaluation of pain.

- Group A: Posterior brachial plexus block with $10 \mathrm{~mL}$ of $0.5 \%$ ropivacaine;

- Group B: Posterior brachial plexus block with $20 \mathrm{~mL}$ of $0.5 \%$ ropivacaine;

- Group C: Posterior brachial plexus block with $5 \mathrm{~mL}$ of $1 \%$ ropivacaine.

The solution of $0.5 \%$ ropivacaine was prepared with $20 \mathrm{~mL}$ of $0.75 \%$ ropivacaine and $10 \mathrm{~mL}$ of sterile bidistilled water for groups $A$ and $B$ whilst on group $C$ it was used the $1 \%$ commercialized standard presentation.

After the block, the patients received general balanced anesthesia with fentanyl (2 to $\left.4 \mu \mathrm{g} . \mathrm{kg}^{-1}\right)$, propofol (2.0 to $\left.2.5 \mathrm{mg} \cdot \mathrm{kg}^{-1}\right)$, and cisatracurium $\left(0.15 \mathrm{mg} \cdot \mathrm{kg}^{-1}\right)$ and sevoflurane (1 to 1.5 CAM). They also received clonidine $\left(1 \mu \mathrm{g} \cdot \mathrm{kg}^{-1}\right)$ and dexamethasone $(10 \mathrm{mg})$ after the anesthetic induction and ondansetron $(4 \mathrm{mg})$, ketoprofen $(100 \mathrm{mg})$ and dipyrone (30 mg.kg-1) immediately after the surgery.

The block was evaluated by verifying the thermal sensitivity using cotton embedded in alcohol following the skin representation of nerve roots from $\mathrm{C} 3$ to $\mathrm{C} 7,30$ minutes after admission to the post-anesthetic recovery room. In the first evaluation, the thermal sensitivity of the skin representation of roots from $\mathrm{C} 5$ and $\mathrm{C} 6$ contralateral to the block was also verified to evaluate the possibility of epidural block. Postoperative pain was evaluated using a visual numeric scale (VNS) ranging from zero (total absence of pain) to 10 (the worst pain possible). The evaluator did not know the concentration of anesthetic injected. In the recovery room, pain evaluation was done 30 minutes after admission and immediately before discharge from the unit. Then, the pain was evaluated by one of the investigators every 8 hours while in the hospital and, on the following day, it was evaluated through telephone contact. To perform the statistical analysis, it was considered the maximum pain and morphine consumption in the recovery room and periods of 12 and 24 hours after being discharged from the unit. All patients received analgesics in a fixed way: intravenous dypirone $2 \mathrm{~g}$ at every six hours and ketoprofen $100 \mathrm{mg}$ at every 12 hours. The patients received venous morphine $4 \mathrm{mg}$ at every four hours if they related pain above three in the VNS.

The groups were compared regarding the time to the first complaint of pain, the VNS score and morphine consumption within the first 24 hours. The length of time to the first complaint of pain was considered from the moment of discharge from the recovery room. The patients were categorized in two groups related to the biggest complaint of pain: group one VNS 0 to 3; group two VNS 4 to 10. This categorization was based on the recommendation of the World Health Organization for the association of opioid in the treatment of moderate to intense pain (ENV 4 to 10$)^{6}$.

The homogeneity of age, weight and height variables was evaluated by Levene's test whereas gender and physical status (ASA) were analyzed by the Chi-square test. The length of time until the first complaint of pain was evaluated by the non-parametric Kruskal-Wallis test, as this variable did not follow normal distribution. The Chi-square test was used to evaluate the other variables. The number of 19 patients in each group was previously calculated so that it could be noticed a difference of two points in VNS betweeen groups with a sampling capacity of $90 \%$ (beta error of $10 \%$ ) and $95 \%$ of trust level (alfa error of $5 \%$ ), considering the standard deviation of 2.1 obtained in similar previous study 7 . All results were considered significant to a significance probability inferior to $5 \%(p<0.05)$.

\section{RESULTS}

All 60 patients completed the study and the blocks were performed without any problem. The analysis of the demographic data shows that there was no statistically significant differen- 
ce between the three groups related to age, weight and height (Table I). There was a prevalence of male patients in group $\mathrm{C}$ and ASA I in group A (Table I).

There was a failure of Brachial Plexus Block in a patient of group $A$, a patient of group $B$ and in two patients of group $C(p=0.717)$. Three patients of group $A$, seven patients of group $B$ and two patients of group $C$ presented a motor block of the hand at the end of the surgery, $(p=0.156)$.
Table II shows the time in hours until the first complaint of pain in the postoperative period and Table III shows the percentage of patients who complained of pain over three in the postoperative period.

There was no difference in time up to the first complaint of pain, VNS group and morphine consumption in the postoperative period between the groups (Figure 1).

Table I - Characteristics of the Patients

\begin{tabular}{lllll}
\hline & Group A $(0.5 \% 10 \mathrm{~mL})$ & Group B $(0.5 \% 20 \mathrm{~mL})$ & Group C $(1 \% 5 \mathrm{~mL})$ & $\mathrm{p}^{* *}$ \\
\hline Age (years) & $50.05 \pm 11.11$ & $49.00 \pm 14.30$ & $47.74 \pm 13.81$ & 0.380 \\
Weight $(\mathrm{kg})^{*}$ & $76.35 \pm 13.79$ & $72.10 \pm 13.33$ & $83.74 \pm 15.47$ & 0.613 \\
Height (meters) & $1.62 \pm 0.21$ & $1.65 \pm 0.07$ & $1.72 \pm 0.08$ & 0.267 \\
Gender (M/F) & $11 / 9$ & $10 / 11$ & $16 / 3$ & $0.045^{* *}$ \\
ASA (I/II) & $17 / 3$ & $12 / 9$ & $9 / 10$ & $0.039^{* *}$ \\
\hline
\end{tabular}

${ }^{*}$ Values expressed in average $\pm S D$; ${ }^{* *} p<0.05$

Table II - Time (hours) Until the First Complaint of Pain in the Postoperative Period

\begin{tabular}{llll}
\hline & Group A $(0.5 \% 10 \mathrm{~mL})$ & Group B $(0.5 \% 20 \mathrm{~mL})$ & Group C $(1 \% 5 \mathrm{~mL})$ \\
\hline $\mathrm{N}$ & 20 & 21 & 19 \\
Average & 18.83 & 19.00 & 18.00 \\
Average $\pm \mathrm{SD}$ & $17.81 \pm 7.23$ & $22.06 \pm 11.47$ & $17.29 \pm 10.29$ \\
\hline
\end{tabular}

SD: standard deviation.

Table III - Evaluation of Pain (VNS)

\begin{tabular}{|c|c|c|c|c|c|}
\hline & \multirow[b]{2}{*}{ VNS } & \multicolumn{3}{|c|}{ Group } & \multirow[b]{2}{*}{$p$} \\
\hline & & A & $\mathrm{B}$ & C & \\
\hline \multirow[t]{2}{*}{ Recovery room } & $0-3$ & $15 / 20(75 \%)$ & $20 / 21(95 \%)$ & $17 / 19(89 \%)$ & 0.148 \\
\hline & $4-10$ & $5 / 20(25 \%)$ & $1 / 21(5 \%)$ & $2 / 19(11 \%)$ & \\
\hline Until 12 hours after discharge from the recovery room & $4-10$ & $2 / 20(10 \%)$ & $1 / 21(5 \%)$ & $3 / 19(16 \%)$ & \\
\hline 12 to 24 hours after discharge from the recovery room & $0-3$ & $11 / 20(55 \%)$ & $13 / 21(62 \%)$ & $9 / 19(47 \%)$ & 0.653 \\
\hline
\end{tabular}

${ }^{*}$ Chi-square.

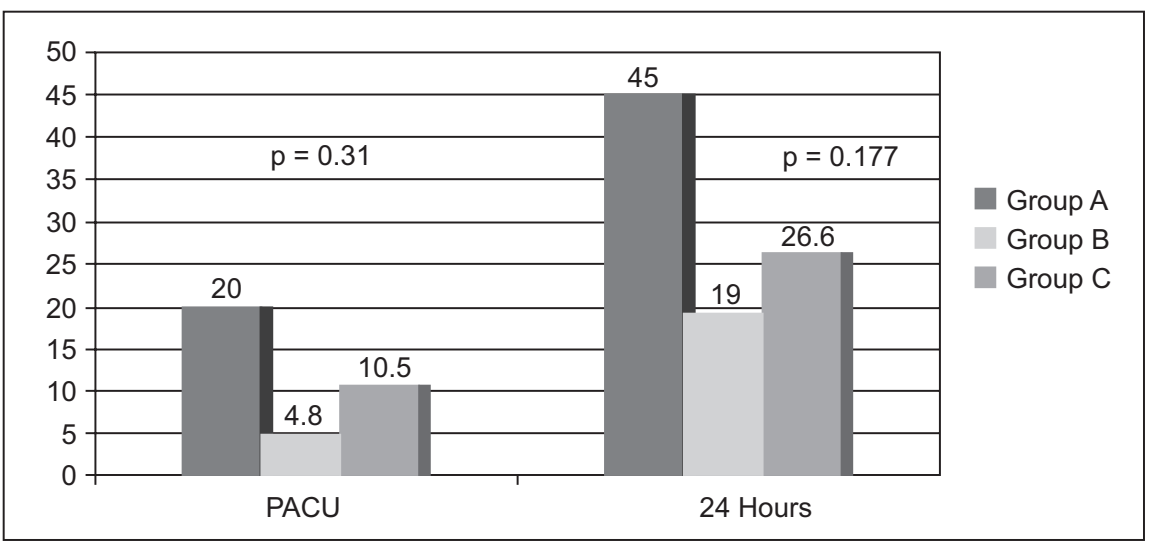

Figure 1 - Percentage of Patients Who Took Morphine.

PACU: Post-Anesthesia Care Unit. 


\section{DISCUSSION}

The arthroscopic surgeries of the shoulder became more frequent as they are less invasive and, therefore, offer a faster recovery. Among the main arthroscopic surgeries of the shoulder are acromioplasty, repair of rotator cuff lesion and treatment of recidivating luxation. Control the pain is one of the main problems in those surgeries, since these procedures are associated with postoperative pain of great intensity and hard to be controlled ${ }^{8,9}$. Among the techniques more commonly employed for this purpose are the use of intravenous opioids associated or not with NSAIDs, the use of articular local anesthetic, suprascapular nerve block and cervical and brachial plexus blocks ${ }^{8-24}$. Among such techniques, brachial plexus block offers the best results on the analgesia 1,3-5,20-21. From the techniques of brachial plexus block, the interscalene block is more commonly used 8,10-12,25,26. Recently, the posterior brachial plexus block, also known as paravertebral cervical block, has received wide attention 1-3,7,27,28. Different volumes of anesthetic have already been employed, but there is no definition of the ideal volume.

It was evident that posterior brachial plexus block with $20 \mathrm{~mL}, 30 \mathrm{~mL}$, and $40 \mathrm{~mL}$ of $0.375 \%$ ropivacaine offerered the same analgesic efficacy in the postoperative period of arthroscopic surgeries of the shoulder ${ }^{27}$. Similarly, it was observed that the increase in concentration from $0.5 \%$ to $0.75 \%$ when $30 \mathrm{~mL}$ of ropivacaine were employed in the interscalene brachial plexus block did not show benefit in the postoperative analgesia of surgeries of the shoulder ${ }^{22}$.

Ipsilateral diaphragmatic paralysis is a common complication expected after brachial plexus block both by the interscalene and the paravertebral cervical approach, due to the block of phrenic nerve (C3-C5 roots), it may occur in $100 \%$ of cases when habitual doses of local anesthetics are used 29,30 . However, paresis, and even total hemidiaphragmatic paralysis, does not lead to respiratory failure in healthy people ${ }^{29}$. On the other hand, in patients with any degree of previous respiratory disease, diaphragmatic hemiparesis and, especially, paralysis may occur with respiratory failure ${ }^{29}$. To avoid diaphragmatic paralysis after brachial plexus block is a benefit to all patients undergoing surgeries of the shoulder, especially obese patients and the ones with pulmonary disease. On the other hand, when brachial plexus block is not performed in those surgeries, the postoperative administration of opioids, pain or both may significantly increase the risk of pulmonary complications and morbidity ${ }^{30,31}$.

A recent study compared interscalene brachial plexus block guided by ultrasonography with $5 \mathrm{~mL}$ and $20 \mathrm{~mL}$ of $0.5 \%$ ropivacaine to perform arthroscopy of the shoulder ${ }^{5}$. The authors concluded that the diaphragmatic paralysis was significantly inferior in the $5 \mathrm{~mL}$ group compared with the $20 \mathrm{~mL}$ group ( $45 \%$ versus $100 \%$ ), $p<0.05$. In addition to that, there was a larger reduction of oxygen saturation in the group that received $20 \mathrm{~mL}(5.85 \%$ versus $1.5 \%), p=0.003$, in the postoperative period. There was no statistically significant difference in pain, quality of sleep and total morphine consumption scales within 24 hours of the end of surgery.

In addition to the benefits of lower incidence of hemidiaphragmatic paralysis, the reduction of volume of local anesthetic is associated with the smaller risk of morbidity related to intravascular injection.

Even though this study did not evaluate the incidence of diaphragmatic paralysis, it was possible to see that the posterior brachial plexus block, with $5 \mathrm{~mL}$ of $1 \%$ ropivacaine with the help of neurostimulator, offered postoperative analgesia similar to $10 \mathrm{~mL}$ and $20 \mathrm{~mL}$ of $0.5 \%$ ropivacaine.

The increase of anesthetic mass $(20 \mathrm{~mL}$ of $0.5 \%$ ropivacaine group) did not mean evident clinical benefit. Since this increase of mass may represent increased risk of toxicity, the use of smaller volume and anesthetic masses seem more interesting. A better strategy to extend the postoperative analgesia would be placing a peripheral catheter with continuous flow, or upon demand of the patient, of low doses of local anesthetic.

A limitation of this study was to use fixed doses of morphine instead of analgesia controlled by the patient to control the escape of pain in the postoperative period and evaluation of analgesic efficacy of different schemes of local anesthetic used. The analgesia controlled by the patient offers a range of advantages compared with the common analgesia, some of them are ${ }^{32}$ : improved analgesia, early relief of pain, more satisfaction and safety when compared with fixed doses of opioid. Although its benefits are well-defined, this analgesia method is still not available in most national institutes owing to cost.

This study concluded that $5 \mathrm{~mL}$ of $1 \%$ ropivacaine promoted analgesic efficacy similar to $10 \mathrm{~mL}$ or $20 \mathrm{~mL}$ of $0.5 \%$ ropivacaine in the posterior brachial plexus block using neurostimulator and without the help of ultrasonography. 


\section{REFERÊNCIAS / REFERENCES}

1. Pippa P, Cominelli E, Marinelli $\mathrm{C}$ et al. - Brachial plexus block using the posterior approach. Eur J Anaesthesiol, 1990;7:411-420.

2. Boezaart AP, Koorn R, Rosenquist RW - Paravertebral approach to the brachial plexus: an anatomic improvement in technique. Reg Anesth Pain Med, 2003;28:241-244.

3. Boezaart AP, de Beer JF, duToit C et al. - A new technique of continuous interscalene nerve block. Can J Anesth, 1999;46:275-281.

4. Beato L, Camocardi G, Imbelloni LE - Bloqueio de plexo braquial pela via posterior com uso de neuroestimulador e ropivacaína a $0,5 \%$. Rev Bras Anestesiol, 2005;45:421-428.

5. Riazi S, Carmichael N, Awad I et al. - Effect of local anaesthetic volume (20 vs $5 \mathrm{~mL}$ ) on the efficacy and respiratory consequences of ultrasound-guided interscalene brachial plexus block. Br J Anaesth, 2008;101:549-556.

6. Vargas-Schaffer G. - Is the WHO analgesic ladder still valid? Twenty-four years of experience. Can Fam Physician, 2010;56(6):514-517.

7. Cruvinel MGC, Castro CHV, Silva YP et al. - Estudo comparativo da eficácia analgésica pós-operatória de $20 \mathrm{~mL}$ de ropivacaína a $0,5,0,75$ ou $1 \%$ no bloqueio de plexo braquial pela via posterior. Rev Bras Anestesiol, 2008;58(5):431-439. 
8. Singelyn FS, Lhotel L, Fabre B - Pain relief after arthorscopic shoulder surgery: a comparison of intraarticular analgesia, suprascapular nerve block, and interscalene brachial plexus block. Anesth Analg, 2004;99:589-592.

9. Ritchie E, Tong D, Chung F et al. - Suprascapular nerve block for postoperative pain relief in arthroscopic shoulder surgery: a new modality? Anesth Analg, 1997;84:1306-1312.

10. Al-Kaisy A, McGuire G, Chan V et al. - Analgesic effect of interscalene block using low-dose bupivacaine for outpatient arthroscopic shoulder surgery. Reg Anesth Pain Med, 1998;23:469-473.

11. D'Alessio J, Rosenblum M, Shea K et al. - A retrospective comparison of interscalene block and general anesthesia for ambulatory shoulder arthroscopy. Reg Anesth Pain Med, 1995;20:62-68.

12. Brown A, Weiss R, Greenberg C et al. - Interscalene block for shoulder arthroscopy: comparison with general anesthesia. Arthroscopy, 1993;9:295300.

13. Savoie F, Field L, Jenkins R et al. - The pain control infusion pump for postoperative pain control in shoulder surgery. Arthroscopy, 2000;16:339-342.

14 Niiyama Y, Omote K, Sumita S et al. - The effect of continuous intra-articular and intra-bursal infusion of lidocaine on postoperative pain following shoulder arthroscopic surgery. Masui, 2001;50:251-255.

15. Henn P, Fischer M, Steuer K et al. - Effectiveness of morphine by periarticular injections after shoulder arthroscopy. Anaesthesist, 2000;49:721-724.

16. Scoggin J, Mayfield G, Awaya D et al. - Subacromial and intraarticular morphine versus bupivacaine after shoulder arthroscopy. Arthroscopy, 2002;18:464-468.

17. Muittari P, Nelimarkka O, Seppala T et al. - Comparison of the analgesic effects of intrabursal oxycodone and bupivacaine after acromioplasty. J Clin Anesth, 1999;11:11-16.

18. Rodola F, Vagnoni S, D'Avolio S et al. - Intra-articular analgesia following arthroscopic surgery of the shoulder. Eur Rev Med Pharmacol Sci, 2001;5:143-146.

19. Park J, Lee G, Kim Y et al. - The efficacy of continuous intrabursal infusion with morphine and bupivacaine for postoperative analgesia after subacromial arthroscopy. Reg Anesth Pain Med, 2002;27:145-149.
20. Axelsson K, Nordenson U, Johanzon E et al. - Patient controlled regional analgesia (PCRA) with ropivacaine after arthroscopic subacromial decompression. Acta Anaesthesiol Scand, 2003;47:993-1000.

21. Klein SM, Nielsen KC, Martín Aliki et al. - Interscalene brachial plexus block with continuos intraarticular infusión of ropivacaine. Anesth Analg, 2001;93:601-605.

22. Klein $\mathrm{S}$, Greengrass R, Steele $\mathrm{S}$ et al. - A comparison of $0.5 \%$ bupivacaine, $0.5 \%$ ropivacaine, and $0.75 \%$ ropivacaine for interscalene brachial plexus block. Anesth Analg, 1998;87:1316-1319.

23. Eroglu A, Uzunlar H, Sener M et al. - A clinical comparison of equal concentration and volume of ropivacaine and bupivacaine for interscalene brachial plexus anesthesia and analgesia in shoulder surgery. Reg Anesth Pain Med, 2004;29:539-543.

24. Neal JM, McDonald SB, Larkin KL et al. - Suprascapular nerve block prolongs analgesia after nonarthroscopic shoulder surgery but does not improve outcome. Anesth Analg, 2003;96:982-986.

25. Laurila $\mathrm{P}$, Löppönen $\mathrm{A}$, Kangas-Saarela $\mathrm{T}$ et al. - Interscalene brachial plexus block is superior to subacromial bursa block after arthroscopic shoulder surgery. Acta Anaesthesiol Scand, 2002;46:1031-1036.

26. Krone S, Chan V, Regan J et al. - Analgesic effects of low-dose ropivacaine for interscalene brachial plexus block for outpatient shoulder surgery: a dosefinding study. Reg Anesth Pain Med, 2001;26:439-443.

27. Cruvinel MGC, Castro CHV, Silva YP et al. - Estudo comparativo da eficácia analgésica pós-operatória de 20,30 ou $40 \mathrm{~mL}$ de ropivacaína no bloqueio de plexo braquial pela via Posterior. Rev Bras Anestesiol, 2007;57(5):500513.

28. Cruvinel MGC, Castro CHV, Silva YP et al. - Prevalência de paralisia diafragmática após bloqueio de plexo braquial pela via posterior com ropivacaína a 0,2\%. Rev Bras Anestesiol, 2006;56(5):461-469.

29. Urmey WF, McDonald M - Hemidiaphragmatic paresis during interscalene brachial plexus block: effects on pulmonary function and chest wall mechanics. Anesth Analg, 1992;74:352-357.

30. Chappell D, Jacob M - Influence of non-ventilatory options on postoperative outcome. Best Pract Res Clin Anaesthesiol, 2010;24(2):267-281.

31. Bonnet $\mathrm{F}$, Marret $\mathrm{E}$ - Influence of anaesthetic and analgesic techniques on outcome after surgery. Br J Anaesth, 2005;95(1):52-58.

32. Palmer PP, Miller RD - Current and developing methods of patient-controlled analgesia. Anesthesiol Clin, 2010;28(4):587-599. 